\title{
Figuras retóricas verbales y visuales en la conformación de un estilo de autor: las caricaturas políticas del semanario satírico francés Le Canard enchaîné
}

ABSTRACT: This work focuses on the study of verbal and visual rhetorical figures, which are basic resources that operate in the political cartoon satirical sub-genre. The corpus consists of 405 political cartoons published by the French weekly satirical newspaper Le Canard enchaîné, the oldest in that country, dealing with the actions and statements of the then President Jacques Chirac (1995-2007) over four periods of analysis selected for their relevance in the socio-political context of France. Based on a methodological approach that articulates a rhetorical-stylistic analysis, and descriptive statistics techniques, we have identified the rhetorical resources in use on the political cartoons considered, paying attention to their interaction; and we have detected stylistic preferences in some of the regular cartoonists of the weekly newspaper. The significantly higher presence of verbal over visual rhetorical figures indicates that the figurative language of Le Canard enchaîné is built mostly from the titles of the cartoons and the dialogues of the characters represented, having a less significant role the graphical representation of the scenario, the objects that compose the image, or even the characters' actions. Our analysis also reveals an independence in the resources used on the represented socio-political context.

Keywords: political cartoon, rhetorical figures, cartoonist, satirical press.

RESUMEN: Este trabajo se centra en el estudio de las figuras retóricas verbales y visuales que operan en la caricatura política, recursos elementales en la constitución de este subgénero satírico. El corpus está conformado por 405 caricaturas políticas publicadas por el semanario satírico francés Le Canard enchaîné -el más longevo de aquel país- que abordan las acciones y declaraciones del entonces presidente Jacques Chirac (1995-2007) durante cuatro periodos de análisis seleccionados por 
su importancia en el contexto socio-político de Francia. A partir de un enfoque metodológico que articula un análisis retórico-estilístico con técnicas provenientes de la estadística descriptiva, se identifican los recursos retóricos más operativos en las caricaturas políticas consideradas, prestando atención a su interacción, y se detectan ciertas preferencias estilísticas en algunos de los dibujantes más asiduos del semanario. La notablemente mayor presencia de figuras retóricas verbales que visuales indica que el lenguaje figurado de Le Canard enchaîné se construye mayormente a partir de los títulos de las caricaturas y de los diálogos de los personajes representados, interviniendo de modo menos marcado la representación gráfica del escenario, de los objetos que componen la imagen, o incluso de las acciones de los personajes. Los análisis efectuados revelan, además, una independencia de los recursos en función del contexto socio-político considerado.

Palabras clave: caricatura política, figuras retóricas, dibujante, prensa satírica.

\section{Introducción}

El término caricatura proviene del latín popular caricare (cargar) y pone énfasis en la representación gráfica exagerada, deformada y ridiculizada de personas o situaciones, al acentuar o disminuir rasgos del rostro o del cuerpo; o al centrarse en ciertos aspectos, dejando de lado otros en el tratamiento de hechos de actualidad. En el terreno de la política, la personalidad caricaturizada da cuenta de una personalización y personificación de los hechos (Tillier, 2005), a partir de la cual situaciones de suma complejidad, decisiones y acciones de un gobierno, recaen bajo la responsabilidad de unos pocos rostros y cuerpos. Los hechos de actualidad constituyen la fuente principal del trabajo de irrisión efectuado por la caricatura política, a partir del cual operan procesos de deconstrucción y alteración.

Este tipo de imagen se enmarca dentro del género satírico puesto que, como la sátira, toma elementos de los discursos ofensivos y los discursos cómicos (Duval y Martinez, 2000) con el fin de denunciar y criticar lo que se consideran como abusos, contradicciones y torpezas de la clase dirigente, haciendo uso de diversas formas de lo cómico.

Por esencia hiperbólica, la caricatura política utiliza una gran diversidad de recursos que le permiten cumplir con esta finalidad, manteniendo como requisito el de garantizar la semejanza entre el personaje dibujado y su referente, asegurando así su relativamente rápida identificación. A la semejanza cabe agregar la simplicidad, la condensación y la economía de/en las representaciones, pues 
unos pocos trazos bastan para dar cuenta de las diferentes facetas que recubren un hecho de actualidad.

En la caricatura política intervienen de forma conjunta signos icónicos, plásticos y lingüísticos, en estrecha relación. Los signos plásticos, como el trazo de la línea plasmado en formas y grosores, el color, la composición y el encuadre, fueron durante mucho tiempo relegados a un papel secundario en las imágenes visuales, frente a un predominio de los signos icónicos. Actúan sin embargo como signos autónomos (ver Grupo $\mu$, 1992) y juegan un rol de gran importancia en las caricaturas, por la deformación característica de este tipo de imagen. Lo lingüístico, por su parte, interviene a través de los títulos que se les asignan a dichas imágenes o a través de las frases atribuidas a los personajes representados e insertas en globos de diálogo, anclando, complementando o contradiciendo lo ícono-plástico. ${ }^{1}$

La representación que el dibujante de caricaturas políticas hace de personas y situaciones tiene un alto grado de esquematización y simplificación puesto que para cumplir con los requisitos de economía, condensación, semejanza y simpleza antes señalados, se apoya en una serie de convenciones y estereotipos visuales y verbales, como por ejemplo, dar cuenta de estados anímicos como la alegría o el enojo mediante la introducción de variaciones en las formas de dibujar ojos, cejas y boca, o la referencia a ideas abstractas a través de símbolos o comparaciones.

Por todas las características específicas señaladas, que guardan relación con su naturaleza discursiva, su función social y argumentativa, además del espacio recurrente que tiene en el periódico informativo o satírico, la caricatura política puede entenderse como un subgénero dentro de la sátira. Dentro de este marco, el dibujante cumple un rol socialmente definido, limitado y previsible (Steimberg, 2001). En este sentido, cabe referirse a la caricatura política como una representación sumamente ritualizada. Esta ritualización es además palpable en cada dibujante, quien desarrolla un estilo de dibujo propio que lo diferencia de los demás.

El trabajo de los dibujantes se encuentra afectado por el periódico para el que trabajan, con una línea editorial más o menos clara y un contrato de lectura particular (Verón, 1985), que instaura un dispositivo de enunciación propuesto por el periódico a sus lectores. En el caso particular de la prensa satírica, que es el que aquí nos ocupa, este contrato comunicacional se funda en un acuerdo tácito entre ambas partes, a partir del cual el lector sabe de antemano que el autor satírico recurrirá a lo implícito y a lo figurado para dar cuenta de los hechos de actualidad $\mathrm{y}$, por lo tanto, que su interpretación no puede quedarse en el sentido propio de lo dicho o representado.

Entre los recursos que la caricatura política utiliza para denunciar, criticar y ridiculizar a los hombres y mujeres políticos, las figuras retóricas juegan un rol

1. Sobre la relación verbal-visual en la caricatura política, ver Pedrazzini (2011). 
fundamental, y se constituyen como elementos centrales en su discurso al asumir diversas funciones como las de atraer, divertir, pasar un mensaje crítico y buscar la complicidad del lector.

De forma conjunta a la caricatura política, otro tipo de imagen mixta -que articula lo verbal y lo visual- aparece con frecuencia en la prensa satírica: la tira, compuesta generalmente de dos a ocho viñetas. La misma reúne las especificidades hasta ahora señaladas, distinguiéndose por el despliegue temporal y espacial que hace en el tratamiento de los hechos de actualidad a través de sus viñetas, organizadas en forma secuencial según una lógica narrativa. En este trabajo haremos preferentemente referencia a la misma como caricatura política de dos o más viñetas.

En base a todo lo dicho, en este trabajo nos preguntamos: ¿qué tipo de figuras retóricas son las de mayor y menor operatividad a nivel lingüístico e ícono-plástico en la caricatura política de una o más viñetas? ¿De qué forma interactúan las figuras retóricas lingüísticas e ícono-plásticas al interior de cada lenguaje-verbal y visual-y entre ambos lenguajes? Si cada dibujante desarrolla un estilo de dibujo propio, ¿es posible que se diferencien también por los recursos que utilizan y por el uso que hacen de lo verbal y lo visual? Por otro lado, teniendo en cuenta la estrecha conexión que la caricatura política tiene con la actualidad, ¿existen variaciones en el uso que se hace de las figuras según el contexto político?

Antes de adentrarnos en nuestro estudio, dedicaremos el próximo apartado a la caracterización de las figuras retóricas y a la presentación de la clasificación que utilizamos para analizarlas.

\section{Definición y clasificación de las figuras retóricas}

La figura retórica es un recurso que permite pasar de un lenguaje propio a un lenguaje figurado, haciendo coexistir un sentido literal y aparente con un sentido latente. Georges Molinié (1993: 113) considera que hay figura en un enunciado «cuando, para el receptor, el efecto de sentido producido no se reduce a aquel normalmente instaurado por la simple combinación léxico-sintáctica de este enunciado». ${ }^{2}$ Marc Bonhomme (1998) identifica en la figura retórica cuatro condiciones: tiene una marca específica en el encadenamiento discursivo; es opcional, en tanto que es posible expresar lo dicho figurativamente de una manera más directa; es mensurable pues su estructura característica se repite en distintos enunciados y es posible reconocerla y categorizarla; y por último, es funcional,

2. Las traducciones de las citas textuales que figuran en este trabajo fueron realizadas por las autoras. 
ya que aumenta el rendimiento argumentativo, estético y afectivo del enunciado que la contiene. Axelle Beth y Elsa Marpeau (2005), por su parte, destacan el alto valor creativo de las figuras, que constituyen un instrumento que permite a sus usuarios la reinvención permanente del lenguaje.

La clasificación de las figuras retóricas es una tarea compleja puesto que no hay coincidencia, entre los especialistas, sobre la cantidad y las características de los grupos que las contienen ni, inversamente, sobre el grupo al que pertenece cada figura. La clasificación tradicional distingue cuatro grupos de figuras que se centran en los niveles semánticos, lógicos, sintácticos y pragmáticos de las frases. Los mismos comprenden las figuras de sentido, los tropos y otras figuras que sirven para «enriquecer la o las significaciones de una palabra al utilizarlas en un contexto inesperado» (Robrieux, 1993: 42); las figuras de palabras, basadas en juegos léxicos y sonoros; las figuras de pensamiento, que refieren «a la relación del enunciado con el sujeto, el orador, y con su objeto, el referente» (Reboul, 1993: 37); y las figuras de construcción, por último, centradas en la sintaxis y el orden de las palabras.

Esta tetrapartición ha sido criticada por algunos expertos como Catherine Fromilhague (2005). Además de haberse puesto en evidencia una interdependencia de los niveles fonográficos, sintácticos, semánticos y referenciales en los cuales intervienen las figuras, las mismas se caracterizan por una dimensión transfrástica. La idea de que hay un «continuum» (Fromilhague, 2005: 20) entre dichos niveles aporta una visión más dinámica sobre cómo operan las figuras.

Para nuestro estudio hemos adoptado una clasificación que recupera la estructura principal de aquella propuesta por Beth y Marpeau (2005) basada en la tetrapartición tradicional, prestando atención al continuum que articula los distintos niveles. Hemos optado por duplicar los cuatro grupos de figuras retóricas en función de la importancia cualitativa y cuantitativa de los tipos de figuras detectados en el corpus analizado. De esta manera, el grupo de figuras de sentido fue dividido en cuatro grupos y el de pensamiento en dos grupos (ver tabla 1).

Esta clasificación nos permite -luego de una serie de adaptaciones- analizar tanto lo lingüístico como lo icono-plástico. La pertinencia de una retórica aplicada a la imagen fue postulada ya hace décadas por, entre otros, Roland Barthes (1960), Dominique Durand (1970) y el Grupo $\mu$ (1992).

En el caso de lo icono-plástico descartamos las figuras de palabras e incluimos al símbolo (en su acepción retórica) dentro del grupo de las metáforas fijas por la alta presencia que tiene en lo visual y por su carácter convencional. Por otro lado, dada la tan elevada presencia en el lenguaje visual de la hipérbola plástica, la sinécdoque y la metonimia del signo, las mismas no fueron consideradas en nuestro corpus puesto que no contribuían a captar matices de interés para nuestro análisis. En el caso de la hipérbola plástica porque hemos dicho que la caricatura opera a través de la exageración y la deformación del objeto representado, y en el de la sinécdoque, porque es una característica habitual la 
de representar en la imagen una parte para dar cuenta del todo. En cuanto a la metonimia de signo, la misma puede ser definida como una figura en la cual «un referente abstracto es representado a través del objeto que lo emblematiza en una cultura dada» (Fromilhague, 2005: 65). Se trata de metonimias materializantes. Extendemos esta acepción para incluir toda representación de lo gestual que busca transmitir sentidos previamente codificados y compartidos en una cultura dada, tales como el enojo, materializado a través del ceño fruncido, o la sorpresa, convencionalmente representada a través de la boca abierta.

\section{Tabla 1}

Categorías de figuras retóricas utilizadas para el análisis

\section{TIPOS DE FIGURAS}

Figuras de palabras

Figuras de contigüidad

Metáforas fijas y lexicalizadas (dentro de figuras de asociación)

Otras figuras de asociación

Figuras de doble sentido

Figuras de construcción

Ironía y sus variantes (dentro de
las figuras de pensamiento)

Otras figuras de pensamiento

\section{DESCRIPCION}

Centradas en la sonoridad, modificación y creación de palabras: asonancia, neologismo, metaplasmo, apócope, geminación, etc.

Tropo que transfiere el sentido entre términos asociados en una misma isotopía. Metonimia, sinécdoque y figuras relacionadas.

Metáfora no creativa, banalizada por el uso.

La metáfora es un tropos que introduce una ruptura de isotopía.

Metáfora creativa (in praesentia, in absentia, etc.), oxímoron, símbolo, y figuras relacionadas.

Trabajan con la polisemia del lenguaje. Calambur, silepsis, juego de palabras, y figuras relacionadas.

Se centran en la simetría, oposición, acumulación, repetición, disposición y estructuración de las palabras: antítesis, paralelismo, elipse, zeugma, entre otras.

Ironía, antífrasis, sarcasmo.

Se centran en la intensidad y dialéctica de las figuras: hipérbole, lítote, personificación, alusión, paradoja y figuras relacionadas. 


\section{Nuestro estudio: objetivos y delimitación del corpus}

Teniendo en cuenta lo planteado anteriormente, los objetivos que guían esta investigación son los siguientes:

- Identificar los tipos de figuras retóricas verbales y visuales que operan con mayor y menor intensidad en la caricatura política de una o más viñetas.

- Indagar acerca de la forma en que las figuras retóricas verbales y visuales interactúan dentro de cada lenguaje y entre ambos lenguajes.

- Estudiar si el uso de las figuras retóricas varía en función del contexto político.

- Analizar si los dibujantes considerados se diferencian en el uso que hacen de las figuras retóricas.

Como parte de una investigación más amplia que se interesa por el tratamiento de la figura presidencial -blanco predilecto de periodistas y dibujantes satíricos- en la prensa satírica (Pedrazzini, 2011), este trabajo toma como objeto de estudio las caricaturas políticas de una o más viñetas que refieren al entonces presidente Jacques Chirac (1995-2007) publicadas en el semanario satírico francés Le Canard enchaîné, el de más larga trayectoria en aquel país, en cuatro períodos de análisis elegidos por su importancia en el contexto político de Francia.

Creado en 1915, Le Canard enchaîné es un periódico de notable influencia y credibilidad en los ámbitos periodísticos y políticos de su país, por su longevidad, la práctica del periodismo de investigación que realiza desde hace décadas, su independencia económica y su extensa red de informantes, ubicados hasta en las esferas de más alto poder. Las ocho páginas que lo componen, de una notable perdurabilidad en cuanto a diseño y contenido a lo largo de las décadas, comprenden cortos textos que revelan rumores, trascendidos y el quehacer diario de la dirigencia política; investigaciones periodísticas; breves notas de color donde se señalan errores de la prensa; crítica de arte; caricaturas de una o más viñetas principalmente centradas sobre la actualidad política, dibujos que ilustran ciertas secciones, entre otros.

Nuestro corpus está constituido por 405 imágenes que refieren directamente a Jacques Chirac, ya sea a través de la representación gráfica del personaje y/o de su mención escrita, de las cuales 372 son caricaturas de una sola viñeta y 33 son tiras que contienen de dos a ocho viñetas. Las imágenes se distribuyen en cuatro periodos históricos que comprenden: 1) el inicio del mandato de Jacques Chirac en 1995 ( 3 meses de análisis; N= 111); 2) la campaña por las elecciones legislativas de 1997 -elecciones que 
fueron anticipadas debido a la decisión del presidente de disolver la Asamblea Nacional- y la consiguiente instauración de un periodo de cohabitación, siendo el Primer Ministro de un partido opositor ( 2 meses de análisis; $\mathrm{N}=72$ ); 3 ) el fin del primer mandato presidencial, la campaña presidencial de 2002 y el inicio del segundo mandato (3 meses de análisis; $N=133$ ) y 4) la campaña por el referéndum a la Constitución Europea en 2005, cuyos resultados negativos suscitaron la nominación de un nuevo Primer Ministro por parte de J. Chirac (2 meses de análisis; $\mathrm{N}=89$ ).

\section{Metodología de análisis}

Adoptamos un enfoque que articuló cuatro etapas diferenciadas. En una primera instancia realizamos un análisis de discurso, desde una perspectiva retórico-estilística, de las imágenes que tratan sobre el presidente Chirac, centrándonos en la identificación de figuras retóricas lingüísticas e icono-plásticas y clasificándolas según la propuesta presentada en la tabla 1. No buscamos dar cuenta de manera total y exhaustiva de las figuras presentes en las imágenes -lo cual nos parece irrealizable dada la inagotable riqueza del lenguaje figuradopero sí apuntamos a realizar un estudio lo más sistemático posible, especificando los criterios considerados para el análisis de cada figura. En casos particularmente complejos, aplicamos un control interjuez que facilitó el reconocimiento de determinadas figuras.

Una vez finalizada la clasificación de todas las figuras retóricas identificadas en el corpus de caricaturas, estudiamos cuantitativamente la distribución de los grupos de figuras. Acto seguido clasificamos y codificamos el corpus según las ocho variables especificadas en la tabla 2 sobre la cual nos explayaremos más abajo, y procedimos a un análisis de correspondencias múltiples (ACM). Esta técnica de análisis multivariado permite describir las relaciones entre diversas variables cualitativas o nominales a partir de su proyección en planos factoriales y formar así grupos entre aquellas modalidades que tienen una contribución a los ejes factoriales superior a la media y que se encuentran próximas entre sí en el plano factorial (Lebart et ál., 1995). Los planos factoriales están formados por dos ejes factoriales ortogonales, cuyas direcciones están establecidas por las modalidades de las variables que diferencian en mayor medida a los individuos -en este caso, las imágenes de Le Canard enchaîné.

Las variables que intervienen en este tipo de análisis pueden ser activas o ilustrativas. Las variables activas son aquellas que contribuyen a la conformación de los ejes factoriales y su incidencia estadística se mide a través de dicha contribución. En cuanto a las variables ilustrativas, si bien estas no intervienen en la 
conformación de los planos, sus modalidades son proyectadas sobre los mismos y su incidencia estadística se mide en función del valor test que alcanzan en esos ejes, fijado en $1,96(\mathrm{p}<0,05)$.

Este análisis fue realizado con el programa SPAD $5.6 \mathrm{~N}$ y se aplicó a las imágenes en las que fueron identificadas figuras retóricas verbales -que como veremos más abajo, son mucho más habituales que las visuales-. El corpus quedó conformado por 358 casos, de los cuales 330 son caricaturas y 28 tiras. Esto quiere decir que no fueron considerados los casos en los que no se detectaron figuras verbales. Estas intervinieron en el análisis como variables activas, mientras que las figuras visuales fueron consideradas como ilustrativas. El número total de variables para ambos casos fue de siete. Si bien para las figuras verbales, nuestra clasificación contempla ocho grupos de figuras, las figuras de contigüidad fueron excluidas del procesamiento por su escasa frecuencia de aparición.

Las catorce variables son dicotómicas puesto que contemplan la presencia o ausencia de cada grupo de figuras retóricas por imagen. Por otro lado, el número de figuras retóricas en cada imagen fue considerado a través de una variable compuesta de cuatro modalidades que informan sobre el número de grupos distintos de figuras retóricas presentes (una figura, dos figuras, de tres a cinco figuras, ausencia de figura). ${ }^{3}$ Esto dio lugar a una variable activa en el caso de lo verbal y una ilustrativa en el caso de lo visual.

Consideramos además otras cinco variables ilustrativas: el periodo de análisis, con cuatro modalidades (1995, 1997, 2002 y 2005); el tipo de imagen, con 2 modalidades (caricatura de una viñeta o caricatura de más viñetas: tira); el autor de la imagen, con 6 modalidades que contienen un autor cada una (Cabu, Cardon, Escaro, Kerleroux, Lefred-Thouron y Pétillon) y 2 modalidades que contienen varios autores cada una, reagrupados por el bajo número de dibujos producidos sobre Jacques Chirac (Brito, Guiraud, Potus, Shertman y Wozniak juntos, con una producción de entre 2 y 8 dibujos cada uno; y Delambre, Kiro y Pancho, con una producción de entre 10 y 16 dibujos); y por último, el registro de lengua, con 4 modalidades (corriente, familiar, popular y/o vulgar, no aplicable puesto que no hay texto escrito). La tabla 2 presenta las variables de análisis consideradas en el ACM.

3. Se contabilizó una sola vez la presencia de alguna de las figuras que componen cada grupo, independientemente de que más de una estuviera presente en una misma imagen. 


\section{Tabla 2}

Dimensiones $^{4}$ y variables de análisis consideradas en el ACM aplicado al corpus de imágenes de Le Canard enchaîné

\begin{tabular}{|c|c|c|c|}
\hline $\begin{array}{l}\text { TIPO DE } \\
\text { VARIABLE/S }\end{array}$ & $\begin{array}{l}\text { NOMBRE DE LA } \\
\text { DIMENSIÓN O } \\
\text { VARIABLE }\end{array}$ & $\begin{array}{l}\text { NÚMERO } \\
\text { DE VARIA- } \\
\text { BLES }\end{array}$ & $\begin{array}{l}\text { NUMERO } \\
\text { DE MODA- } \\
\text { LIDADES }\end{array}$ \\
\hline $\begin{array}{l}\text { Nominal o cualitati- } \\
\text { va activa }\end{array}$ & Figuras retóricas lingüísticas & 7 & 14 \\
\hline Nominal activa & $\begin{array}{l}\text { Número de figuras lingüísti- } \\
\text { cas en cada imagen }\end{array}$ & 1 & 4 \\
\hline Nominal ilustrativa & $\begin{array}{l}\text { Figuras retóricas ícono-plás- } \\
\text { ticas }\end{array}$ & 7 & 14 \\
\hline Nominal ilustrativa & $\begin{array}{l}\text { Número de figuras ícono- } \\
\text { plásticas en cada imagen }\end{array}$ & 1 & 3 \\
\hline Nominal ilustrativa & Periodo de análisis & 1 & 4 \\
\hline Nominal ilustrativa & Tipo de imagen & 1 & 2 \\
\hline Nominal ilustrativa & Autor & 1 & 8 \\
\hline Nominal ilustrativa & Registro de lengua & 1 & 4 \\
\hline
\end{tabular}

\section{Las figuras retóricas verbales y visuales, recursos centrales en la caricatura política}

\subsection{Distribución cuantitativa de las figuras retóricas}

Desde un punto de vista cuantitativo, el número de tipos de figuras retóricas diferentes identificados en lo verbal es mucho más elevado que en lo visual. De 555 figuras en el primer caso (es decir, más de una figura por imagen), pasamos a 228 en el segundo, lo cual representa $41 \%$ más de figuras lingüísticas.

En cuanto a los grupos de figuras más recurrentes (ver figura 1), las metáforas fijas y creativas y los símbolos reúnen 59\% de los casos en lo visual mientras que en lo verbal alcanzan un 19\%. La metáfora constituye, en efecto, un recurso

4. Hablamos de dimensión cuando la misma contiene más de una variable. 
especialmente apto para la asociación visual de hechos o ideas, tan característica en la imagen satírica, mientras que el símbolo es de gran utilidad para condensar sintéticamente -a través de un signo- una idea abstracta, consensuada culturalmente, tal el caso de los signos religiosos.

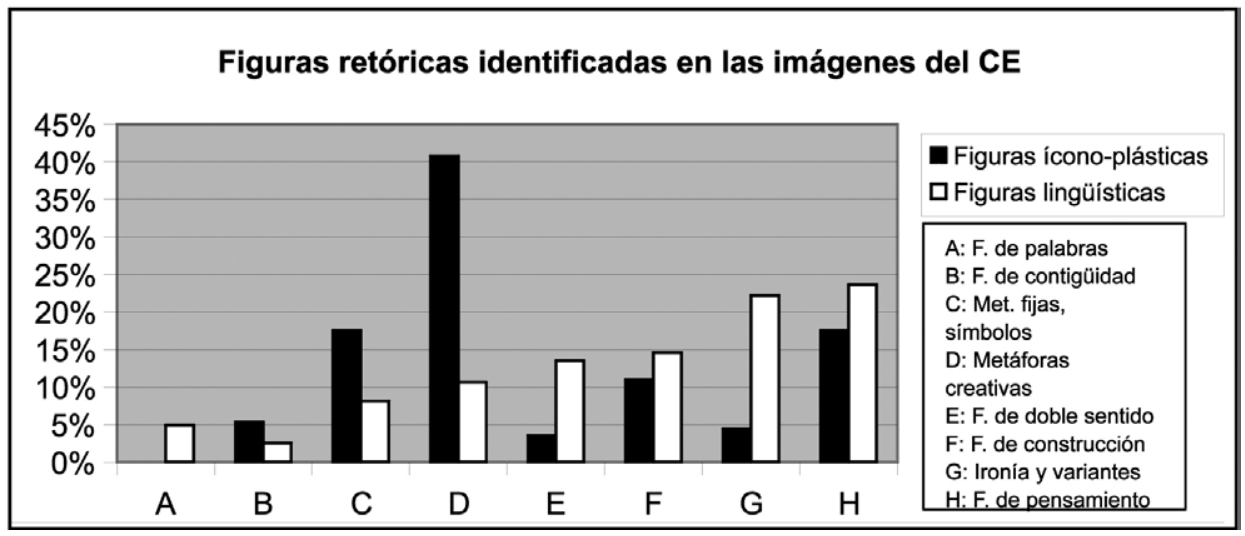

Figura 1

Distribución de los grupos de figuras lingüísticas e icono-plásticas detectadas en el corpus analizado

Las figuras de doble sentido presentan igualmente una diferencia a destacar puesto que mientras que en lo verbal representan un $14 \%$ de los casos, en lo visual totalizan un 4\%. Esto puede obedecer, en parte, a una mayor variedad de figuras lingüísticas. En el caso de lo icónico-plástico, estas se limitan a la silepsis, que se produce cuando un mismo signo reenvía a dos sentidos diferentes. Dos ejemplos de silepsis serían el vapor de una cacerola o el agua que se salpica al zambullirse en una piscina presentes en dos caricaturas, que toman la forma de una nube de hongo, haciendo referencia a la decisión tomada por Jacques Chirac al inicio de su primer mandato, de retomar los ensayos nucleares en el Atoll de Mururoa, en el Pacífico.

La figura 1 pone igualmente en evidencia que el lenguaje verbal es un terreno más propicio para la ironía y sus variantes: de $22 \%$ identificadas en este caso, se pasa a tan solo $4 \%$ en el lenguaje visual. La ironía es un recurso muy apreciado en los discursos satíricos, que permite, entre otras posibilidades, la toma de distancia del autor de una caricatura con respecto al enunciado citado, frecuentemente ridiculizado a través de la exageración y el absurdo. 
Las figuras de pensamiento y en particular la alusión, por su parte, tienen mucha importancia en ambos lenguajes, siendo las más frecuentes dentro de las figuras lingüísticas. A través de esta figura, se propone un juego al lector, quien debe descubrir el sentido oculto, vehiculizado a través de aquellas «referencias implícitas y oblicuas a un elemento exterior al universo del enunciado» (Fromilhague, 2005: 117). Gérard Genette (1982) menciona a la alusión -junto al plagio y a la cita- como uno de los tres casos de intertextualidad, entendida como la presencia efectiva de un texto en otro texto.

Los grupos de figuras restantes, de contigüidad y de construcción, no presentan una diferencia muy marcada, inferior al 5\%, con respecto a su presencia en el lenguaje verbal y en el visual. Recordemos que dos tipos de figuras de contigüidad muy habituales en lo icónico-plástico son las sinécdoques y las metonimias de signo, que fueron excluidas de la cuantificación por razones ya explicitadas.

\subsection{Análisis de correspondencias múltiples}

En función de los resultados obtenidos en el ACM que tuvo las figuras retóricas lingüísticas como variables activas, nuestro análisis se centró en el primer plano factorial (ver figura 2). Allí se identifican cuatro grupos principales de modalidades que asocian presencia y ausencia de figuras retóricas lingüísticas e ícono-plásticas, autores y registros de lengua. Ninguno de los periodos considerados ni los tipos de imagen (caricatura o tira) forman parte de estos grupos.

Un primer grupo asocia las caricaturas de una o más viñetas de los dibujantes Lefred-Thouron y René Pétillon ${ }^{5}$ con el registro de lengua corriente, la ironía verbal y sus variantes y la ausencia de figuras visuales. Entre las figuras poco características de estos dibujantes se encuentran, a nivel verbal, las de doble sentido y las metáforas fijas, y a nivel visual, las metáforas creativas. Se trata entonces de un estilo de humor más verbal que visual y particularmente irónico.

Un ejemplo de este grupo es una caricatura de Lefred-Thouron titulada irónicamente «La mejor del año», que se publicó poco tiempo antes de la segunda vuelta de las elecciones presidenciales de 2002 en la que Jean-Marie Le Pen, de la extrema derecha, se enfrentó a J. Chirac. En esta imagen aparece J. Chirac desayunando con su mujer Bernadette, quien tiene un periódico en sus manos. Su esposa le dice sarcásticamente: "¡Amigo mío, hete aquí usted como la virtuosa muralla moral de la República!», lo cual suscita que el personaje presidencial se atragante.

5. Cuatro de los ejemplos de caricaturas que damos en este trabajo pueden consultarse en Pedrazzini (2011: 293-294). 
Este le responde: «iBernadette... no cuando bebo!». ${ }^{6}$ El dibujante hace aquí referencia a la imagen deshonesta que circula del Presidente en la opinión pública, quien de hecho debió enfrentar varios procesos por malversación de fondos y enriquecimiento ilícito, entre otras acusaciones. Ante el temor de que avanzase la extrema derecha, muchos opositores a J. Chirac manifestaron su intención de votarlo en segunda vuelta y por lo tanto pusieron en segundo plano las dudas que existían en torno a él sobre posibles casos de corrupción. Este tipo de imagen, en la que la pareja presidencial comparte un desayuno y Bernadette Chirac hace comentarios sarcásticos a su marido, son muy características de Lefred-Thouron.

El segundo grupo asocia las caricaturas de André Escaro con el uso de un registro familiar. El humor satírico de este dibujante se diferencia del resto por la utilización de numerosas figuras retóricas verbales en una misma imagen: tres a cinco en el texto y a diferencia de los autores del primer grupo, utiliza de manera característica el doble sentido y las figuras centradas en la sonoridad, la alteración y creación de palabras. Por el contrario, hace menos uso de la ironía y de otras figuras de pensamiento. Sus caricaturas se caracterizan por el uso de una o dos figuras visuales diferentes, en particular metáforas creativas y fijas y símbolos.

Un ejemplo que corresponde a este grupo es una caricatura de A. Escaro publicada durante la campaña por el referendum sobre la Constitución europea que se realizó el 29 de mayo 2005. J. Chirac se encuentra parado frente a tres carteles, de los cuales el «sí» y el «no» (a la Constitución) indican la misma dirección y un «quizás» indica la dirección contraria. Con notable inquietud -gotas de transpiración salen de su rostro-, el personaje exclama: « $\mathrm{A} A h$, así, m’ habría tirado una bala referendum-dum en e' pie!?». ${ }^{7}$ Aquí pueden citarse cuatro figuras retóricas diferentes. A nivel exclusivamente lingüístico, la repetición de la sílaba «dum» corresponde a una reduplicación o epizeuxe, que interviene a su vez como una armonía imitativa (Beth y Marpeau, 2005) en tanto que dicha repetición simula el sonido de dos balas. Escaro articula así estrechamente aspectos formales y de contenido. Los apócopes en francés «j', m', l'» que figuran en nota al pie dan lugar a un registro familiar que sirve para construir la imagen de un personaje que se expresa sin cuidar mucho su lenguaje en el círculo privado, acorde con la imagen que circulaba en la opinión pública. En un plano mixto, verbal y visual, cabe mencionar la paradoja de los carteles.

El tercer grupo asocia las caricaturas del dibujante Jean-Marie Kerleroux con el registro familiar, el uso combinado doble de figuras lingüísticas, entre las cuales se destacan las figuras de pensamiento, y la utilización de una figura

6. «Mon ami, vous voici le vertueux rempart moral de la République!», - «Khof! Bernadette... pas quand je bois!».

7. «Alors, comme ça, j' m'aurais tiré une balle référendum-dum dans l'pied!?». 
ícono-plástica. Ninguna de estas aparece de forma distintiva pero sí emerge la ausencia de la ironía.

Una caricatura de Kerleroux publicada el mismo día que la citada de LefredThouron, el 24 de abril de 2002, hace referencia al mismo escenario político -la segunda vuelta de las elecciones presidenciales-y con las mismas implicancias. La imagen se titula «Mutación» y allí está representado J. Chirac quien se dice irónicamente a sí mismo: "Ya está, ahora pasé a ser el "Super-recurso"》». Con esta palabra compuesta (dentro de las figuras de palabra), Kerleroux hace alusión al personaje Chirac del programa televisivo de sátira política Les Guignols de l'Info, al que lo llaman «Supermentiroso».

El cuarto grupo comprende una asociación entre modalidades lingüísticas e icono-plásticas: la presencia de una figura en el texto, la ausencia de figuras verbales de pensamiento y la utilización de la ironía en lo visual. Ningún dibujante en particular se asocia a estas modalidades.

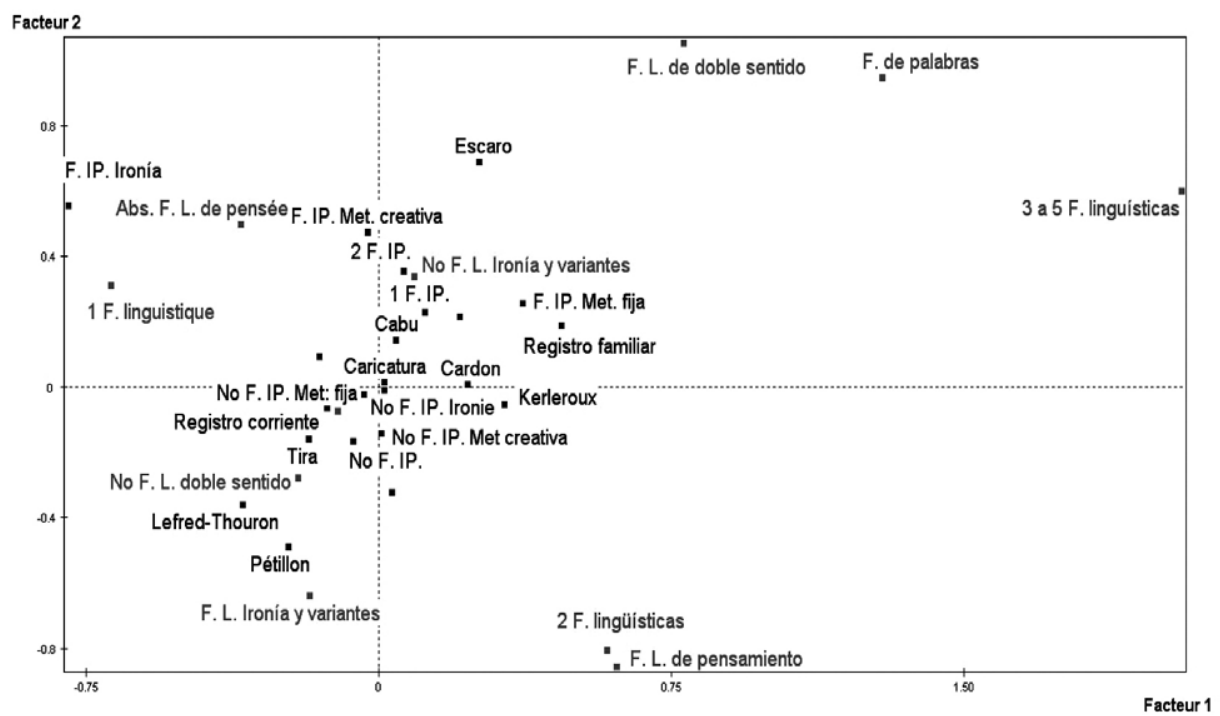

Figura 2

Primer plano factorial con aquellas modalidades activas que tienen una contribución superior a la media y con las modalidades ilustrativas que alcanzaron el valor test (1.96). Por una cuestión de legibilidad, las demás modalidades fueron suprimidas, exceptuando las 6 modalidades de dibujantes individuales presentadas en la sección metodológica

8. «Et voilà, je suis devenu "Super-recours"». 
Con el fin de profundizar en la identificación de un estilo en el uso que los diversos dibujantes hacen de las figuras, consideramos los cinco primeros ejes factoriales para establecer asociaciones entre dibujantes y figuras retóricas. El caso más notable es el de Cabu, el dibujante con mayor producción en el semanario francés, quien se caracteriza por el uso de dos figuras icono-plásticas, metáforas fijas y creativas e ironía, y una figura lingüística, de las que se destaca la metáfora creativa. El estilo de este autor se diferencia entonces de los demás por la construcción de analogías verbales y visuales y por el recurso poco frecuente a la ironía icono-plástica.

Un ejemplo que presentaremos aquí es una caricatura publicada antes de la primera vuelta de las elecciones legislativas de 1997, titulada: «¿La $1^{\text {era }}$ vuelta tendrá tanto éxito como el $5^{\circ}$ elemento?». Allí Cabu representa la contienda electoral haciendo una analogía entre los políticos y los superhéroes. Dos bandos se enfrentan en el espacio, los que pertenecen al gobierno de Chirac y los socialistas, cada uno con una pancarta (eslogan real de campaña de cada uno): la de los oficialistas dice «Impulso compartido» ${ }^{9}$ mientras que la de los adversarios dice «Cambiemos el futuro». ${ }^{10}$ Lejos del enfrentamiento, sentado cómodamente en un transporte espacial individual se encuentra J. Chirac, quien exclama: « ¡Tomo al vencedor!», ante lo cual J. M. Le Pen, grotescamente dibujado y con lo que pareciera un arma en la mano, responde: «... Yo también». ${ }^{11}$ El dibujante establece una doble analogía, verbal y visual, entre la muy taquillera película de Luc Besson El Quinto elemento y la campaña legislativa. Los personajes Chirac y Le Pen pretenden tomar al vencedor pero por razones distintas. En el caso de Chirac podrían ser válidas dos interpretaciones opuestas: está confiado de que su partido ganará y por lo tanto no se inquieta, o bien prefiere mantenerse distante de la contienda electoral para no verse perjudicado si su partido llega a perder. En el caso de Le Pen, existe menos ambigüedad en cuanto a la interpretación: espera al vencedor para eliminarlo (!). La forma grotesca en la que este último está dibujado, con una boca y dientes muy grandes, puede identificarse como una hipérbola visual, que va más allá de la mera exageración de ciertos rasgos del rostro, al servir a una finalidad crítica.

Si focalizamos, a continuación, en la manera en que las figuras interactúan considerando los dos primeros ejes factoriales, podemos afirmar que los recursos lingüísticos que más tienden a aparecer -con tres o más ocurrencias-son los de doble sentido y los de palabras, que no son necesariamente los más frecuentes, según pudo apreciarse en la figura 1. La gran popularidad de estos dos grupos de

9. «Élan partagé».

10. «Changeons d'avenir».

11. «Je prends le vainqueur!». - «...Moi aussi!». 
figuras puede obedecer, en el caso de las figuras de palabras, al recurso habitual por parte de los dibujantes de jugar con el ritmo y la sonoridad de las palabras (como es el caso de la caricatura de Escaro citada); y en el caso de las figuras de doble sentido, al juego que se instaura principalmente con palabras polisémicas.

En cuanto a la combinación doble de figuras en el texto, observamos una asociación entre las figuras de pensamiento tales como la alusión, la paradoja y la sustitución con la ironía, la antífrasis (caso puntual de ironía) y el sarcasmo. Esta combinación potencia el trabajo con lo implícito, solicitando una participación particularmente activa por parte del lector. Cuando la asociación se da entre la alusión y la ironía, las figuras más frecuentes en ambos grupos, el lector debe simultáneamente reconstruir las referencias externas al universo del enunciado y detectar que lo dicho es contrario o distinto a lo que el autor quiere dar a entender. La ironía también se caracteriza por aparecer sola en las imágenes, actuando en estos casos como elemento estructurante y condicionante del enunciado.

En los casos en los que dos figuras ícono-plásticas operan en forma conjunta, la metáfora creativa es la más solicitada, lo cual se explica por el enorme potencial de este tipo de figura para asociar ideas o hechos, tal como se ha señalado más arriba.

\section{Conclusiones}

El discurso satírico que predomina en las caricaturas políticas de Le Canard enchaîné encuentra una base importante en las figuras retóricas, tanto a nivel verbal como visual, a través fundamentalmente de la alusión, la ironía, la metáfora fija y creativa y el doble sentido. El uso de un doble lenguaje, en el que se superpone un sentido oculto y un sentido aparente, promueve la complicidad de un receptor avezado. Le Canard enchaîné desafía a sus lectores con analogías inesperadas, referencias que no guardan relación con los hechos de actualidad tratados, distancias entre lo que se dice y se pretende dar a entender, pero recompensa los esfuerzos con la satisfacción que suscita el reconocimiento de lo que subyace en el mensaje. Dicha satisfacción será tanto más grande en los casos en los que el sentido oculto es más difícil de detectar. La interpretación de los códigos apropiados puede suscitar en el lector sentirse parte de un club exclusivo.

La gran diferencia con respecto a la cantidad y diversidad de las figuras identificadas en lo verbal y en lo visual -59\% más en el primer caso-, pone de manifiesto que los recursos generadores de sátira y humor en las caricaturas del semanario francés privilegian lo verbal por sobre lo visual. De esta manera, los títulos que acompañan las imágenes o bien los globos atribuidos a los personajes concentran una buena parte del sentido figurado vehiculizado, interviniendo de modo menos marcado en la constitución de un lenguaje figurado la representación gráfica del escenario, de los objetos que componen la imagen, o incluso de las acciones de los personajes. Este resultado es consistente a lo obtenido en otros estudios (Pedrazzini y Scheuer, 2010). 
A través del ACM hemos podido descartar que el uso de las figuras retóricas varíe según el contexto político considerado, es decir que las mismas permanecen estables con el tiempo, lo cual está en concordancia con los resultados del análisis de los títulos de Le Canard enchaîné que realizamos en otra instancia de la investigación. Por otro lado, la nula asociación entre figuras retóricas y tipo de imagen (caricatura de una o más viñetas, tira) pareciera indicar que los dibujantes no privilegian determinado tipo de figuras según se trate de uno u otro tipo de imagen. Sin embargo, para confirmar este resultado, sería necesario realizar un estudio específico, con un corpus más importante de tiras.

El ACM puso en evidencia ciertas asociaciones entre grupos de figuras retóricas, como la ironía y sus variantes y otras figuras de pensamiento como la alusión. Además hizo posible detectar que algunos grupos de figuras tienden a operar de manera conjunta en una misma imagen, tal el caso de las figuras de sentido y de palabras que se asocian a tres o más figuras.

La asociación entre ciertos grupos de figuras y algunos de los dibujantes más asiduos del periódico indica preferencias retórico-estilísticas que están operando en la elaboración de las caricaturas. Esto sugiere que el estilo de autor no solo está determinado por la manera de dibujar, con trazos gruesos o finos, con mayor o menor grado de esquematización, o de representar caricaturalmente tal o tal personaje, poniendo un énfasis diferencial en ciertos rasgos. El estilo de autor también está determinado por los recursos lingüísticos e ícono-plásticos puestos en juego. Algunos dibujantes como Lefred-Thouron y Pétillon optan por un humor predominantemente verbal, con fuerte presencia de la ironía y el sarcasmo, y poco recurso a analogías visuales. Escaro, por su parte, produce caricaturas con alta densidad de figuras lingüísticas que se centran en juegos de sonoridad, ritmo y sentido y se sirve de convenciones visuales o gráficas para representar ideas abstractas. Kerleroux recurre de forma distintiva a la alusión verbal mientras que Cabu juega con la construcción de escenarios ficticios en los que son representados los dirigentes políticos, sirviéndose de la metáfora creativa verbal y visual.

El enfoque en cuatro etapas implementado para el estudio de las imágenes de Le Canard enchaîné, en el que se articuló un análisis retórico-estilístico, el análisis de frecuencias, la categorización y codificación de las variables consideradas, y el análisis de correspondencias múltiples, permitió un abordaje bastante integral del objeto de estudio. Fue posible trabajar de forma sistemática con un vasto corpus, identificar regularidades y realizar un análisis simultáneo de diversas categorías, prestando atención a la interacción entre las mismas. Pero, por otro lado, la toma en consideración de ejemplos puntuales permitió observar más de cerca cómo operan las figuras retóricas en las caricaturas políticas así como hacerse una idea de cómo eligió determinado autor tratar algunos hechos políticos de gran relevancia. 


\section{Agradecimientos}

Esta investigación fue parcialmente financiada por CONICET (PIP 1029), la Agencia Nacional de Promoción Científica y Tecnológica (PICT 06-1607) y la Universidad Nacional del Comahue (B139).

\section{Referencias bibliográficas}

Barthes, R. (1964): «Rhétorique de l'image», Communications, 4: 40-51.

Beth, A.; E. Marpeau (2005): Figures de style, París, Librio Mémo.

Волномме, М. (1998): Les figures clés du discours, París, Éditions du Seuil.

Durand, J. (1970): «Rhétorique et image publicitaire», Communications, 15: 70-95.

Duval, S.; M. Martinez (2000): La satire, París, Armand Collin.

Fromilhague, C. (1995): Les figures de style, París, Nathan.

Genette, G. (1982): Palimpsestes. La littérature au second degré, Saint-AmandMontrond, París, Editions du Seuil.

Grupo $\mu$. (1992): Traité du signe visuel. Pour une rhétorique de l'image, París, Le Seuil.

Lebart, L.; A. Morineau; M. Piron (1995): Statistique exploratoire multidimensionnelle, París, Dunod.

Molinié, G. (1993): La stylistique, París, PUF.

Pedrazzini, A. (2011): La construction de l'image présidentielle dans la presse satirique: vers une grammaire de l'humour. Jacques Chirac dans l'hebdomadaire français Le Canard enchaîné et Carlos Menem dans le supplément argentin Sátira/12. Tesis doctoral en Ciencias de la Información y de la Comunicación, Universidad París-Sorbonne. Portal e-sorbonne: http:// www.e-sorbonne.fr/theses/construction-1-image-presidentielle-presse-satirique-vers-grammaire-1-humour-jacques-chirac-1

Pedrazzini, A.; N. Scheuer (2010): «La interacción lingüística e ícono-plástica en la producción de caricaturas políticas: un estudio funcional y retórico». IRICE Nueva época, 21: 95-111.

Reboul, O. (1993): La rhétorique, París, Presses Universitaires de France.

Robrieux, J. (1993): Eléments de rhétorique et d'argumentation, París, Dunod.

STEimberG, O. (2001): «Sobre algunos temas y problemas del análisis del humor gráfico», Signo y seña, 12: 99-118.

Tillier, B. (2005): A la charge! La caricature en France de 1789 à 2000, París, L'Amateur.

VERón, E. (1985): «L'analyse du 'contrat de lecture': une nouvelle méthode pour les études de positionnement des support presse», en Les médias. Expériences, recherches actuelles, application, París, Institut de Recherches et d'Etudes Publicitaires, pp. 203-230. 